\section{AIDS and the gay community: the doctor's role in counselling}

As alarm caused by the rising number of cases of the acquired immune deficiency syndrome (AIDS) spreads through the gay male community its members will increasingly turn to doctors for help and advice. Such consultations will be most helpful if the doctors concerned are fully aware of the diagnostic indicators of this syndrome and its associated conditions_-and are also familiar with gay lifestyles and resources within the gay community.

Patients concerned about sexually transmitted AIDS will fall into one or more of the following groups: those with AIDS; those with associated conditions, including those with antibodies to the causative virus (HTLV-III); notified sexual contacts of people with AIDS; regular homosexual or heterosexual partners of people with AIDS; and other gay men worried about the disease.

General practitioners and general physicians may well choose to refer all symptomatic cases to a department of genitourinary medicine, but non-specialists are likely to become concerned in continuing care. Patients in all categories may present with the same degree of anxiety and seeking information and advice on a whole range of problems-medical, psychological, and psychosexual. The information given must be accurate and understandable. Present evidence suggests that most people with antibodies to the human $\mathrm{T}$ cell lymphotropic virus HTLV-III (including those who have had sexual contact with patients with AIDS) do not become ill. They do, however, need an opportunity to discuss the implications of the finding for their sexual behaviour and related problems of infection control. This virus has been isolated from blood, saliva, and semen, so any contacts with these fluids may be assumed to confer an increased risk of infection. ${ }^{1}$ The principal risk factors identified are those which maximise such transmission of these fluids from one person to another. Passive anal intercourse and contact with a large number of sexual partners are behaviours incurring the greatest risk. These data have formed the basis of the "safer sex" guidelines produced by the Terrence Higgins Trust and offered in various counselling settings and in our literature.

For many doctors the psychosexual aspects of consultations will be the most problematic. Nowhere is this more apparent than in discussions of sexual behaviour. Not all gay men have a large number of sexual partners. In those who do we need to recognise that many factors may contribute to their behaviour. Before the attendant medical risks included AIDS, in some cases such "recreational sex" might have been part of a well adjusted lifestyle. In others it might have expressed a difficulty in establishing friendships in the pubs and clubs of the gay "scene"-and the comparative ease of finding sexual partners. Furthermore, people are found in all sections of society who have severe problems in forming social relationships and who use sex to relieve their loneliness. Finally, there are many gay and bisexual men who are unable to express their sexuality in any context other than as a response to their sexual needs. Many married men are in these circumstances. All these differences have implications for a doctor who wishes to discuss changes in sexual behaviour. A lifestyle cannot be altered overnight without regard to the need to restructure pivotal attitudes. Referral to an appropriate gay counselling organisation may help in redefining attitudes to sexual behaviour and relationships.

Sometimes the doctor will be consulted by a man whose anxiety about AIDS seems to be out of all proportion to his actual risk. As with other diseases there may be many reasons for this, but the fear of AIDS is particularly associated with sexual guilt-either because of the sexual mode of transmission or as a perceived link between the disease and homosexuality itself. These people need to develop some acceptance of their sexuality before their anxieties can be allayed. Specialist counselling can usually be offered, however, and a local or national gay switchboard can help to place referrals. As AIDS becomes increasingly widespread doctors should encourage the provision of counselling services by hospitals and community groups.

Whether occasioned by the disease itself or by the wish to avoid it the associated fear and loss of familiar ways of functioning may produce clinically important degrees of anxiety and depression. In all but the most extreme cases these may be continued successfully by some form of group or individual supportive counselling. Such counselling is rarely offered. The psychology department at St Mary's Hospital, London W2, provides an encouraging exception. Also the Terrence Higgins Trust is actively concerned in providing such services in its own right and in cooperation with St Mary's Hospital.

A valuable source book for insights into the realities of the lives of gay men is Jack Babuscio's We Speak for Ourselves. ${ }^{2}$ Further information on the work of the Terrence Higgins Trust and copies of our free leaflets on AIDS and gay men can be obtained by telephoning us on 012788745 .

G LEACH

Clinical director

A WHITEHEAD

Terrence Higgins Trust, Chairman London WCIN 3XX

1 Melbye M, Biggar RJ, Ebbesen P, et al. Seroepidemiology of HTLV-III antibody in Danish homosexual men: prevalence, transmission, and disease outcome. $\mathrm{Br}$ Med $\mathrm{J}$ 1984;289:573-5. 2 Babuscio J. We speak for ourselves. London: SPCK, 1976.

\section{AIDS and the health professions}

Anxiety about the acquired immune deficiency syndrome (AIDS) is understandable; it is an incurable disease with an ominous prognosis. Though it is still rare-7981 cases in the United States and 118 in Britain (January figures) - all the predications are that numbers will continue to rise sharply. The epidemiological features remain unchanged, with the disorder being very unusual outside established groups at risk (homosexuals, intravenous drug abusers, people from the Caribbean and central Africa, and haemophiliacs). Nevertheless, awareness that AIDS may develop in the sexual partners and infants of those at risk, after the transfusion of blood and plasma derivatives, together with the widespread misconception that AIDS is contagious, has provoked a good deal of public and professional concern. Irrational fears are rife, especially among hospital staff who have, or are likely to have, casual contact with patients with 
AIDS or specimens taken from them. "Could I catch AIDS?" is a question that will be asked with increasing frequency in Britain, and doctors need to be informed so that they can offer sensible advice not only to possible patients and their relatives but also to anyone else who may have become needlessly alarmed.

AIDS is attributed to an infection with human $T$ cell lymphotropic virus type III (HTLV-III), and this virus has been isolated repeatedly from the blood, semen, and saliva of affected individuals. It has also been isolated from asymptomatic homosexuals and haemophiliacs. AIDS with its associated opportunistic infections or Kaposi's sarcoma or both is only one end of a range of clinical conditions caused by HTLV-III which includes persistent generalised lymphadenopathy and various combinations of fatigue, weight loss, fever, diarrhoea, and oral candidiasis. Infection results in the full blown syndrome of AIDS in only a minority of cases, but it is not known whether asymptomatic carriers of the virus are any more or less infectious than those with overt disease. Nor is it certain how many carriers go on to develop AIDS, or an AIDS related disease, because there seems to be a time lapse of up to five years between documented infection and the onset of symptoms.

The diagnosis of AIDS and its related conditions is essentially a clinical one backed up by the finding of immunological abnormalities. There is no one pathognomonic test. Further confirmation may be obtained by testing for antibodies to HTLV-III-but as yet tests for these "marker" antibodies can be carried out only in very few centres in Britain, and the results may take three to four weeks to come through. Commercial testing kits should shortly become widely available, though some are thought to give false positive results. American studies of the prevalence of antibody to HTLV-III suggest that $85-100 \%$ (depending on the assay) of patients with AIDS or progressive lymphadenopathy and of homosexuals with symptoms are seropositive. In a recent British study anti-HTLV-III was detected in $17 \%$ of homosexuals at risk and $34 \%$ of haemophiliacs, but the risk of haemophiliacs going on to develop AIDS, or an AIDS related condition, appears to be much less than that of homosexuals. (An excellent practical guide entitled AIDS and the Blood has recently been published and, although primarily for haemophiliacs, gives helpful advice to all those concerned with the donation and transfusion of blood. $\left.{ }^{1}\right)$ Tests in unselected blood donors gave negative results, but HTLV-III antibody was found in $42 \%$ of the contacts of patients with AIDS or progressive lymphadenopathy. ${ }^{2}$

AIDS is transmitted by close contact (usually sexual) and through parenteral transmission by infected blood and plasma products. Recently seroconversion has been documented after transmission of the virus by accidental self inoculation of blood, ${ }^{3}$ but absorption of putative infected material through broken skin or mucous membranes is a theoretical rather than a proved risk.

The DHSS recently published guidelines for good practice for hospital and laboratory staff in direct contact with patients with AIDS or specimens from them. ${ }^{4}$ The guidelines were drawn up by the Advisory Committee on Dangerous Pathogens, and, though their "interim" nature has been emphasised, their implications have caused a great deal of concern in many service departments. For if the recommendations are to be interpreted strictly (and pressure from hospital staff may ensure that they are) each department that handles or is expected to handle suspected AIDS specimens could be expected to provide a separate room with special equipment that is "dedicated" for the purpose. The more $\underset{7}{\frac{0}{7}}$ extensive experience in the United States suggests that such $\frac{\mathbb{D}}{2}$ precautions are unnecessary, and common sense dictates that $\frac{Q}{c}$ Britain would do well to follow that example.

In essence the American policy entails following the procedures that are already established for dealing with 7 specimens from known or suspected cases of hepatitis B. This means a tightening of standard procedures to ensure? that spillage and "splash" from machines are kept to a" minimum, surfaces are kept clean, and staff report accidents $\overrightarrow{\overrightarrow{0}}$ promptly. Cuts or abrasions must be covered appropriately. $\overrightarrow{0}$ Ideally patients suspected of having AIDS should be man-흘 aged in a ward or special cubicle where the nursing staff and $\stackrel{\bar{m}}{\overrightarrow{5}}$ other hospital workers are familiar with the handling and $\stackrel{\mathbb{Q}}{\circ}$ disposal of potentially infected specimens. The DHSS guidelines suggest that suspected AIDS specimens should be $\vec{\circ}$ flagged in a way that differentiates them from other"infectious" specimens. Whether this will serve any purpose $\vec{\infty}$ other than to fuel the anxiety of those who are already reluctant to handle these specimens is questionable. Routine safety precautions should be adequate- - view backed up by a recent study in which HTLV-III antibody was found in none of 85 hospital employees with nosocomial exposure to specimens from patients with AIDS.

The fact that tens of thousands of hospital workers in $\underset{\omega}{\infty}$ America - and probably several thousand in Britain - haved been exposed to the virus and yet none has developed AIDS옹 is reassuring for it suggests that it is appreciably less $\tilde{\omega}$ infectious than hepatitis $\mathbf{B}$. There are, therefore, no grounds 7 to suggest that transmission occurs via the aerosol route or via응 casual contact-or, to put it simply, by sharing a bus or a waiting room or by talking to or shaking hands with a patient with AIDS. Doctors have a responsibility to put the record $\vec{\infty}$ straight and help people view the disease in perspective; patients with AIDS not only need our professional help but: also our sympathy and understanding.

1 Jones P. AIDS and the blood: a practical guide. London: Haemophilia Society, 1985 2 Cheingsong-Popov R, Weiss RA, Dalgleish A, et al. Prevalence of antibody to human T. lymphotropic virus type III in AIDS and AIDS-risk patients in Britain. Lancet 1984;ii:477-80. Anonymous. Needlestick transmission of HTLV-III from a patient infected in Africa [Editorial]. Lancet 1984;ii:1376-7.

4 Advisory Committee on Dangerous Pathogens. Acquired immune deficiency syndrome (AIDS) Advisory Committee on Dangerous Pathogens. Acquired

intenm guidelines. London: DHSS, 1984. (HC (85) 1.)
Hirsch MS, Wormser GP, Schooley RJ. Risk of nosat

lymphotropic virus III (HTLV-III). N Engl f Med 1985;312:1-3.

位

\section{Lectins}

In 1888 at the University of Dorpat, Estonia (now in the $\stackrel{\frac{7}{2}}{\text {. }}$ USSR), Stillmark was studying the toxicity of castor oil seeds N (Ricinus communis), but, finding his conscience troubled by స્ట the suffering of the animals in his experiments, he chose tog work in vitro. Mixing an extract of $R$ communis seeds witho blood, he made the startling observation that the erythrocytes were agglutinated and the plasma coagulated. ${ }^{1}$ Thus ${ }^{\text {? }}+?$ began a train of research that culminated in the assassination $\frac{0}{0}$ on a London street of Gyorgi Markov in $1978,{ }^{2}$ and on its way $\underset{\odot}{\circ}$ cast powerful side illumination on to diverse topics such as $\frac{?}{0}$ immunology, botany, oncology, ecology, microbiology, genetics, biochemistry, allergy, and nutrition.

The haemagglutinin of $R$ communis is just one of a huge 8 group of plant agglutinins also known as phytohaemagglutinins. This term is ambiguous, however, for it also describes 